\title{
Learning through Problem Solving: How Case Based Learning Can Foster Pathology Education
}

\author{
Alfred Roy ${ }^{1}$, Elizabeth Armitage ${ }^{2}$, Nabeel Khan ${ }^{3}$, Brian Acevedo Fuentes ${ }^{4}$ \\ 1Department of Pathology Basseterre St. Kitts and Nevis \\ 2 Pathology student Basseterre, St. Kitts and Nevis \\ ${ }^{3}$ Pathology student, Basseterre St. Kitts and Nevis \\ ${ }^{4}$ Pathology student Basseterre, St. Kitts and Nevis
}

\begin{abstract}
.
With the introduction of core competencies in training medical students, schools have redefined learning objectives. Core competencies have included communication skills into all Basic Sciences courses. Most medical schools have adopted an integrated curriculum which includes small group learning. The students working in groups transcends diverse backgrounds and learn to communicate effectively. Here, at UMHS we are introducing small group learning using clinical cases. Students work together to solve cases and present them. Case Based Learning (CBL) has been used extensively in US medical schools with great success.

BACKGROUND: Patient care in today's medicine is interdisciplinary. The role of the Pathologist is that of one who makes a definitive diagnosis and interpret various ancillary lab tests. In recent years the importance of Basic Sciences and how it relates to Clinical Medicine has come to the fore. It has been suggested that medical students in Pathology should know the mechanisms which underlie diseases, know how to diagnose them using histopathology/labs, and apply these to clinical scenarios. Competencies also stresses the need for having excellent communication skills. Communication skills is a must to reduce errors and improve patient management. Introduction of integrated Basic Sciences with self-assessments is the way to improve communication skills. Using Problem Based Learning (PBL), Team Based Learning (TBL), and Cased Based Learning (CBL) in recent years have helped in improving learning as it more engaging, encourages collaboration within student groups, and improving communication skills.

OBJECTIVES: The purpose of this presentation to show how CBL improves learning Pathology.

METHODS: Analysis created from Examsoft and survey examines performance of 80 students.

FINDINGS: Results are awaited.

DISCUSSION: CBL in Pathology has shown that students learn better in groups. Teamwork transcends diverse backgrounds and improves communication skills. UMHS Pathology department plans to build cases which covers learning objectives effectively.
\end{abstract}

Keywords: Case Based Learning, Teamwork, Communication skills 